\title{
Crucial Role of Covalent Surface Functionalization of Clay Nanofillers on Improvement of the Mechanical Properties of Bio-epoxy Resin
}

\author{
V-S. Vo ${ }^{a, b}$, S. Mahouche-Chergui ${ }^{a,{ }^{*}}$, V-H. Nguyen ${ }^{b}$, S. Naili ${ }^{b}$, B. Carbonnier ${ }^{a,{ }^{*}}$ \\ a) Université Paris-Est, ICMPE (UMR 7182), CNRS, UPEC, 2 Rue Henri Dunant, 94320 Thiais, F- 94320 THIAIS \\ France \\ b) Université Paris-Est, Laboratoire Modélisation et Simulation Multi-Echelle, MSME UMR 8208 CNRS, 61 \\ avenue du Général de Gaulle, Créteil Cedex 94010, France
}

Total number of pages $=2$

Total number of figures $=3$ 


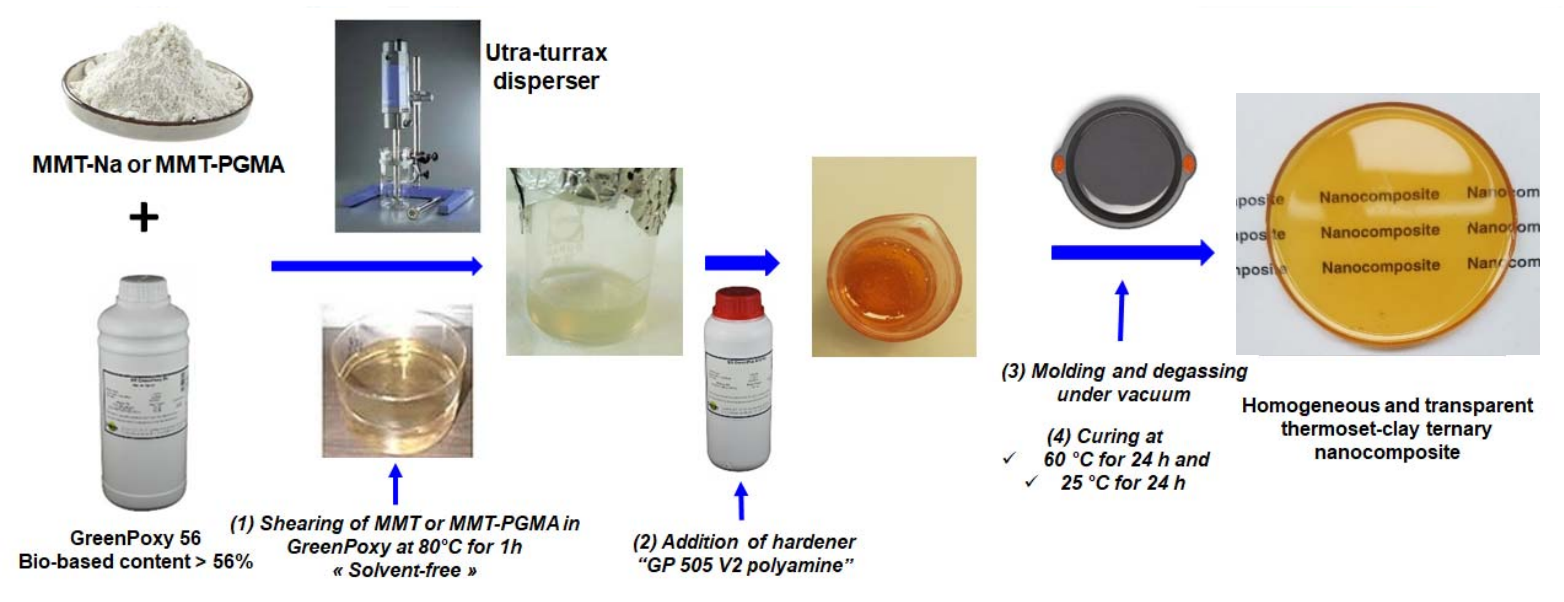

Figure S1. Schematic illustration of dispersion of neat clay and epoxy-rich clay nanofillers (MMT-PGMA) into the bio epoxy resin matrix.

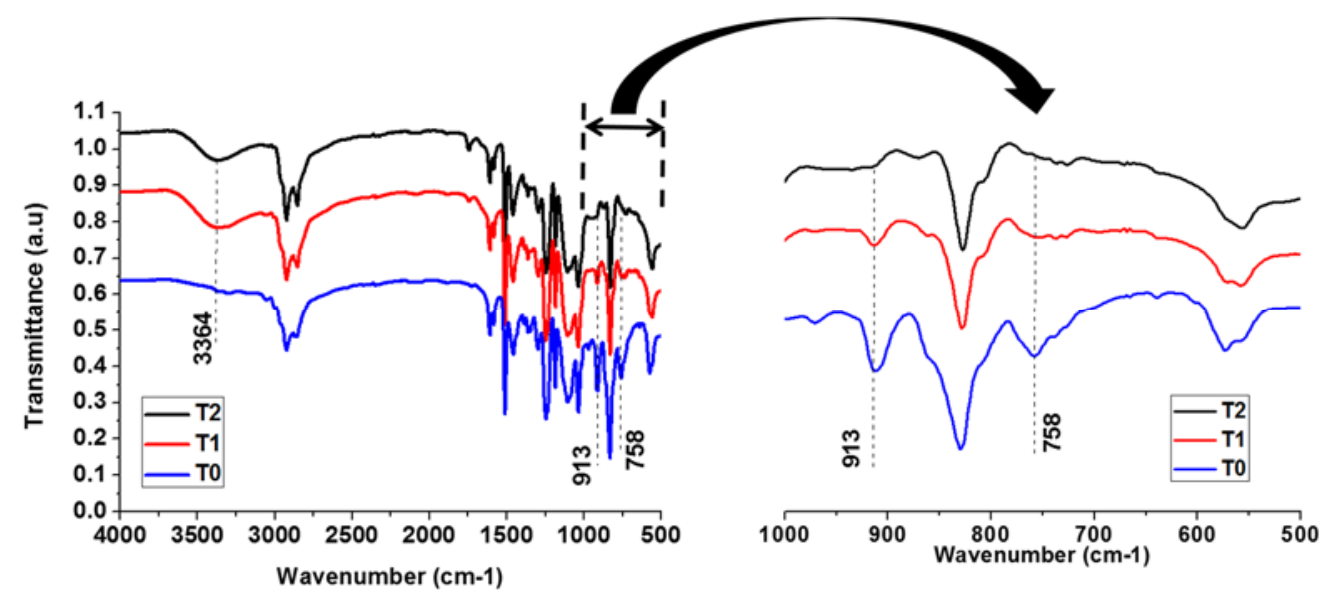

Figure S2. Spectra of resin epoxy-hardener system at $60{ }^{\circ} \mathrm{C}$ and at different crosslinking times $\mathrm{T} 0$ (0 minute), T1 (40 minutes) and T2 (12h)

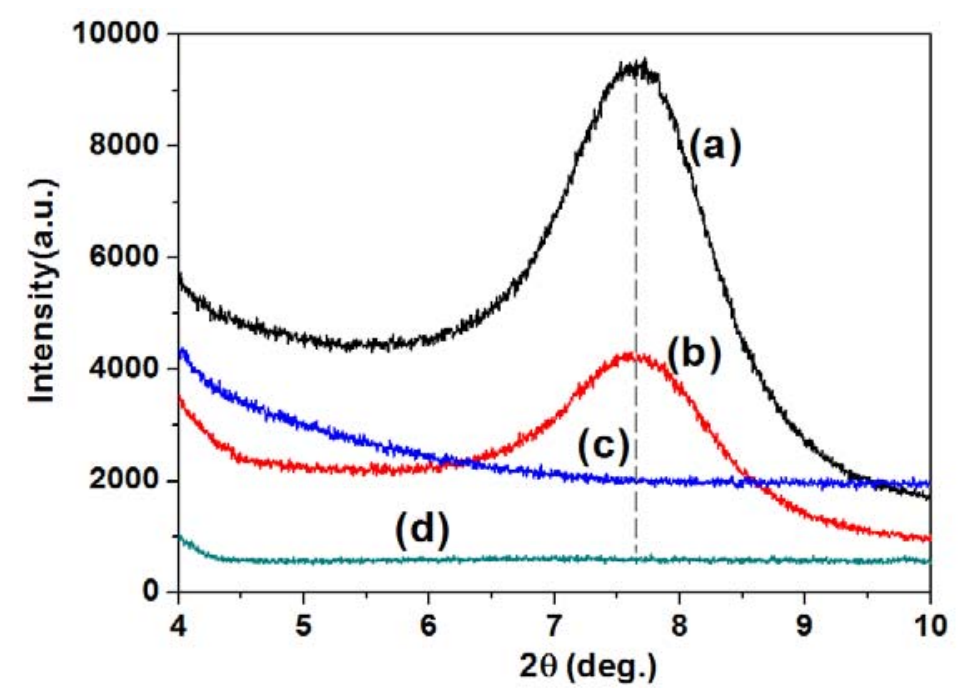

Figure S3. XRD patterns of (a) MMT-Na, (b) MMT-Na/Bioepoxy nanocomposite 2 wt.\%, (c) MMTPGMA-2h and (d) MMT-PGMA-2h/Bioepoxy nanocomposite 5 wt.\%. 